\title{
$\mathrm{PSO}$ 를 이용한 퍼지 모델의 구조 최적화
}

\section{Structure Optimization of Fuzzy Model Using PSO}

\author{
김 두 현*한 병 조** 이 석 용*** 양 해 원 ${ }^{*}$ \\ (Doo-Hyun Kim $\cdot$ Byung-Jo Han $\cdot$ Sok-Yong Lee $\cdot$ Hai-Won Yang)
}

\begin{abstract}
This paper proposed PSO-Fuzzy controller design method. We could improve the learning performance of fuzzy controller by using PSO algorithm, which had recently showed its robust of performance while solving various difficult optimization problems. In other words, our aim was to forward the controller is performance by deciding fuzzy model structure that had good performance on optimization of the controller, based on PSO. During a simulation, we could see whether the mobile robot could convergence on the final goal or not, and also see the error, and through this process, we found out that this controller is more robust than the conventional controller.
\end{abstract}

Key Words : PSO, Fuzzy model, PSO-fuzzy, Mobile robot

\section{1. 서 론}

PSO(Particle Swarm Optimization)는 어류나 조류의 무리 들에 흔하게 관찰할 수 있는 생체 군집(Swarm)의 사회적 행 동을 기반으로 하는 군집 기반의 진화 연산 기법(Evolutionary Computation)으로 1995년에 J. Kennedy와 R. Eberhart에 의 해 제안되었다[1]. 어류나 조류의 무리와 같은 생체 군집의 구성원들이 무리를 지어 돌아다니며 스스로의 경험과 다른 구성원들에게서 얻은 정보로 목적지를 찾아가는 것과 같이, $\mathrm{PSO}$ 에서는 개체(Particle)들이 군집을 이루며 자기 자신의 경험과 무리 전체에 공유되어있는 정보를 사용하여 다차원 의 탐색공간에서 최적의 해를 찾아간다.

퍼지 제어는 1965년 Zadeh가 제안하였으며, 일반적으로 시스템의 특성이 복잡하여 기존의 정량적인 방법으로 해석 할 수 없거나, 얻어지는 정보가 부정확하고, 불확실한 경우 에 사용한다[2]. 퍼지 제어의 성능은 퍼지 규칙에 의존하며 보다 좋은 성능을 위해서는 퍼지 규칙의 최적화 방법이 필 요하다[3]. 따라서 본 논문에서 제안한 퍼지 제어기는 PSO 알고리즘을 이용하여 퍼지 모델의 구조를 최적화 과정에 적 용하였다. 또한 제안된 모델의 성능 향상을 평가하기 위해 이동 로봇을 이용하여 다양한 경로를 추적하고 기준이 되는 경로와의 오차와 수렴 속도를 통하여 성능을 확인하였으며, $\mathrm{PSO}-$ 퍼지제어기를 적용한 이동 로봇의 경로 추적은 경로 추적 오차의 수렴을 보장하고 기존의 제어기보다 좋은 성능 을 보여주고 있다.

\footnotetext{
* 준 회 원 : 한양대 전자전기제어계측공학과 석사과정

** 정 회 원 : 한양대 전자전기제어계측공학과 박사과정

**** 비 회 원 : (주)삼현 상무이사

† 교신저자, 펠로우회원 : 한양대 전자컴퓨터공학부 교수·공박

E-mail : hwyang@hanyang.ac.kr

접수일자 : 2012년 1월 3일

최종완료 : 2012년 3월 28일
}

\section{2. 본 론}

본 논문에서는 제안된 제어기의 성능 향상을 확인하기 위 해 2 개의 바퀴로 구동되는 이동 로봇에 적용하여 경로 추적 제어기를 설계하였고, 다양한 경로에 따른 기준 경로의 추적 성능을 확인하도록 한다. 이동 로봇에 적용되는 퍼지 제어 기는 PSO 알고리즘을 이용하여 퍼지 모델의 구조를 최적화 하여 결정한다.

\subsection{PSO(Particle Swarm Optimization)}

$\mathrm{PSO}$ 라 불리는 군집기반의 진화연산 기법은 다차원의 탐 색공간에서 최적의 해를 찾아내는 것으로, 효과적인 탐색을 수행하기 위해서는 적합한 탐색 알고리즘을 적용한다.

모든 개체들은 적합도 함수(Fitness function)에 의해 평 가된 각각의 값을 가지고 있다[4]. 세대(Generation)를 거듭 하는 동안 지나온 지점에서 가장 좋은 적합도 값을 가진 위 치벡터를 pbest(Particle best)라 부르고 모든 개체들의 pbest 중에서 전반적으로 최적의 적합도 값을 가지고 있는 위치벡 터를 gbest(Generation best)라 부른다.

$\mathrm{PSO}$ 알고리즘은 다음과 같다 (Algorithm 1) :

1 단계 : 개체를 탐색공간 내에서 임의로 생성한다. 이 개 체들을 pbest로 설정하고 이들이 초기 군집을 구성한다.

개체 $i$ 는 총 $n$ 개가 존재하며, 각 개체들의 속도 벡터 $\left(v_{i}=v_{1}, v_{2}, \cdots, v_{n}\right)$ 와 위치 벡터 $\left(x_{i}=x_{1}, x_{2}, \cdots, x_{n}\right)$ 는 각각 식 (1)과 식 (2)를 이용하여 임의로 생성된다.

$$
\begin{aligned}
& v_{i}=v^{\min }+\frac{v^{\text {max }}-v^{\text {min }}}{20} \operatorname{rand}() \\
& x_{i}=x^{\text {min }}+\left(x^{\text {max }}-x^{\text {min }}\right) \operatorname{rand}()
\end{aligned}
$$


여기서, $v^{\min }$ 와 $v^{\max }$ 는 최소, 최대 제한 속도이고, $x^{\min }$ 와 $x^{\max }$ 는 최소, 최대 위치 경계이다. $\operatorname{rand}()$ 은 $[0,1]$ 사이에서 균등 분포된 임의의 값이다.

2 단계 : 생성된 개체들은 적합도 함수(Fitness function) 식 (3)을 이용하여 평가된다.

각 세대에서 개체의 적합도 값들은 이전 세대의 각 개체 의 적합도 값과 비교하여 이전 세대 값보다 좋으면 pbest로 저장되며, 전체 군집의 pbest 중 가장 좋은 적합도 값을 가 진 개체는 gbest로 저장된다.

$$
F\left(x_{i}^{k}\right)=f i t\left(x_{i}^{k}\right)
$$

3 단계 : 모든 개체들에 대해 식 (4)를 이용하여 새로운 속도를 업데이트한다.

$$
\begin{gathered}
v_{i}^{k+1}=w(k) v_{i}^{k}+c_{1} \operatorname{rand}()\left(\text { pbest }_{i}^{k}-x_{i}^{k}\right)+c_{2} \operatorname{rand}()\left(\text { gbest }_{i}^{k}-x_{i}^{k}\right) \\
v_{i}^{k+1}= \begin{cases}v^{\max }, & \text { if } v_{i}^{k+1}>v^{\max } \\
v_{i}^{k+1}, & \text { if } v^{\min } \leq v_{i}^{k+1} \leq v^{\max } \\
v^{\min }, & \text { if } v_{i}^{k+1}>v^{\min }\end{cases}
\end{gathered}
$$

여기서, $v_{i}^{k}$ 는 $k$ 번째 세대의 $i$ 번째 개체 속도이다. $c_{1}$ 과 $c_{2}$ 는 가속 상수(Acceleration constant)이다. $w(k)$ 는 관성 하중 (Inertia weight)으로 군집의 최종 수렴을 위한 제어 파라미 터이며, 관성 하중 값이 클 경우에는 전역 탐색(Global Search)이 강화되지만 지역 극소에 빠지기 쉽다. 반대로 값 이 작을 경우에는 지역 탐색(Local Search)이 강화되지만 속도가 느려지게 되는 문제점이 발생한다. 수렴 속도를 결 정하는 관성 하중은 최적의 값을 구하기 위해 식 (5)을 이 용한다. $w_{\min }$ 는 최소 관성 하중 값이고, $w_{\max }$ 는 최대 관성 하중 값이다.

$$
w(k)=w_{\max }-\frac{w_{\max }-w_{\min }}{N} k
$$

4 단계 : 전 단계에서 구해진 속도를 가지고 식 (6)을 이 용하여 새로운 개체들을 구한다.

$$
\begin{aligned}
x_{i}^{k+1} & =x_{i}^{k}+v_{i}^{k+1} \\
x_{i}^{k+1} & = \begin{cases}x^{\max }, & \text { if } x_{i}^{k+1}>x^{\max } \\
x_{i}^{k+1}, & \text { if } x^{\min } \leq x_{i}^{k+1} \leq x^{\max } \\
x^{\min }, & \text { if } x_{i}^{k+1}>x^{\min }\end{cases}
\end{aligned}
$$

5 단계 : 최대 세대에 도달하거나, 적합도 조건이 만족할 때 알고리즘을 종료하게 된다. 조건에 만족하지 않을 때에 는 2 단계부터 반복한다.

알고리즘의 종료 후 탐색공간상의 최적 위치는 마지막 세 대에 생성된 gbest가 된다.

\section{2 퍼지 모델}

시스템이 선형일 경우에는 정확한 모델이 가능하지만 시 스템이 비선형일 경우에는 큰 오차와 많은 제약 조건이 있 다. 오차를 줄이고 제약 조건을 제거하기 위해 퍼지 모델을 이용한다[5].

퍼지 모델은 경험과 지식을 기반으로 하여 제어 시스템은 IF-THEN 형식의 언어적인 규칙을 통해 모델링한다. 언어 적인 규칙을 기반으로 시스템의 특성과 제어 특성을 모두 포함하여 추론과정을 통해 제어기의 역할을 수행한다.

따라서 모델의 입력에 대하여 출력은 퍼지 추론에 의해 구해진다. 퍼지 모델의 일반적인 구조는 그림 1 과 같이 표 현된다.

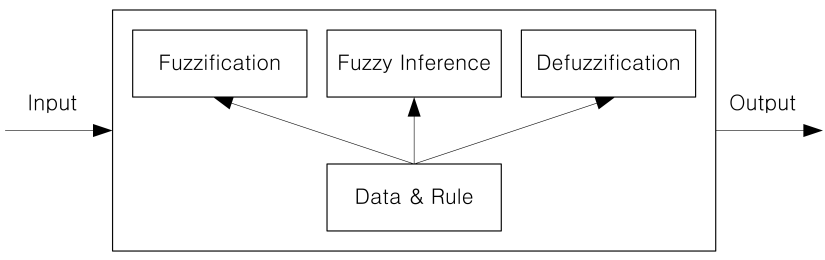

그림 1 퍼지 모델의 구조

Fig. 1 The general structure of the fuzzy model

퍼지 모델은 크게 퍼지화기(Fuzzification), 규칙 베이스 (Rule base)를 포함한 퍼지 추론부(Fuzzy Inference), 그리고 비퍼지화기(Defuzzification)로 구성된다.

추론 방법으로는 일반적으로 많이 사용되는 Mamdani의 추론 방법인 Min-Max 방법을 사용한다. 퍼지 규칙 식 (7) 과 식 (8)은 전반부(Premise)와 후반부(Consequent)가 퍼지 명제로 된 IF-THEN 형식으로 서술된다[6][7].

$$
\begin{gathered}
R_{y 1}\left(j_{1}, j_{2}\right): \text { IF } x_{1} \text { is } A_{\left(1, j_{1}\right)} \text { AND } x_{2} \text { is } A_{\left(2, j_{2}\right)}, \\
\text { THEN } y_{1} \text { is } y_{1(j 1, j 2)} \\
j_{1}, j_{2} \in\{-2,-1,0,1,2\} \\
R_{y^{2}}\left(j_{3}, j_{4}\right): \text { IF } x_{3} \text { is } A_{\left(3, j_{3}\right)} \text { AND } x_{4} \text { is } A_{\left(4, j_{4}\right)}, \\
\text { THEN } y_{2} \text { is } y_{2(j 3, j 4)} \\
j_{3}, j_{4} \in\{-2,-1,0,1,2\}
\end{gathered}
$$

여기서, $x_{i}$ 는 $i$ 번째 입력 변수이고, $A_{(i, j)}$ 는 $j$ 번째 규칙의 소속 함수 집합이다. $y_{i}$ 는 $i$ 번째 출력 변수이고, $y_{i(j, j)}$ 는 $j$ 번 째 규칙의 소속 함수이다.

본 논문에서는 입력과 출력 변수의 값들을 0 에서 1 사이의 값으로 정규화 하였으며, 각 입력 변수들을 $\mathrm{NB}$ (Negative Big), NM(Negative Middle), NS(Negative Small), $\mathrm{ZO}$ (Zero), PS(Positive Small), PB(Positive Big) 5개로 균등 분할하였다. 


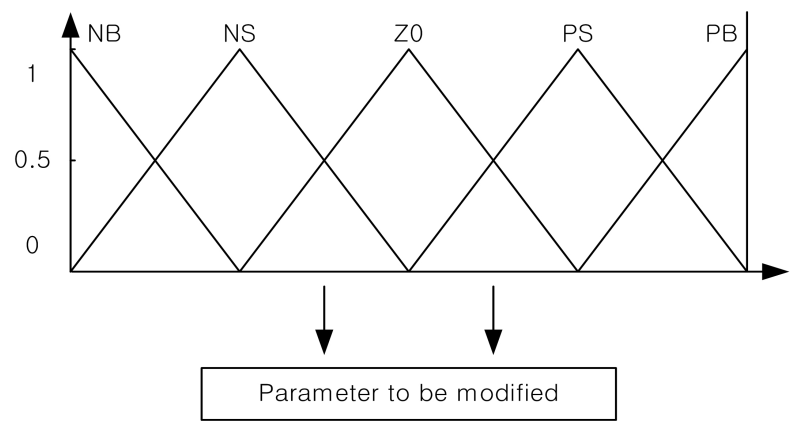

그림 2 소속 함수

Fig. 2 Membership function
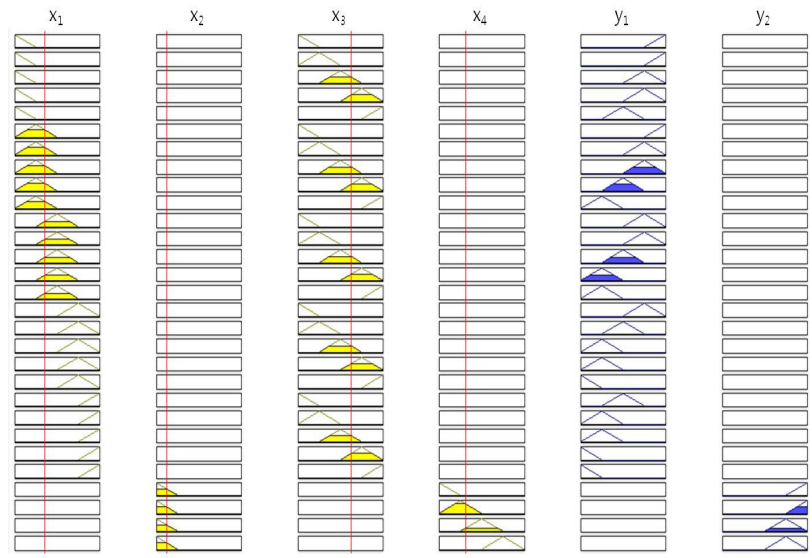

그림 3 소속 함수 최적화 결과

Fig. 3 Membership function optimization results

퍼지 시스템의 입력과 출력 공간을 분할하여 이동 로봇의 움직임을 세분화하였다. 그림 3은 FIS(Fuzzy Inference System)을 사용하여 전문가의 지식으로 얻은 데이터들을 기반으로 결정한 퍼지 제어기의 소속 함수이다.

표 $\quad 1$ 퍼지 규칙

Table 1 Fuzzy rules

\begin{tabular}{|c|c||c|c|c|c|c|}
\hline \multicolumn{2}{|c||}{$y_{1}, y_{2}$} & \multicolumn{5}{c|}{$x_{1}, x_{3}$} \\
\cline { 2 - 7 } & NB & NS & ZO & PS & PB \\
\hline \hline \multirow{7}{*}{$x_{2}, x_{4}$} & NB & PB & PB & PS & ZO & ZO \\
\cline { 2 - 7 } & NS & PB & PS & PS & ZO & NS \\
\cline { 2 - 7 } & ZO & PS & PS & ZO & NS & NS \\
\cline { 2 - 7 } & PS & PS & ZO & NS & NS & NB \\
\cline { 2 - 7 } & PB & ZO & NB & NS & NB & NB \\
\hline
\end{tabular}

\subsection{PSO-퍼지 제어기}

본 논문에서는 주어진 시스템의 입력 데이터에 따라 효율 적으로 비선형을 표현하는데 있어서 매우 중요한 역할을 가 지는 전반부 구조를 최적화한다. 전반부 구조에서 퍼지 규 칙의 전반부 입력 변수의 선택과 퍼지 구현 규칙의 수를 선 택해 줌으로써 성능을 개선시키도록 한다.

일반적인 퍼지 모델의 경우 각 입력 변수마다 소속 함수
의 수를 정해 주여야 한다. 또한, 각각의 입력들과 소속 함 수의 수를 고려하여 분할하게 된다. 결과적으로 입력 변수 가 많아지거나 입력 변수마다 정해진 소속 함수의 수가 많 아질수록 퍼지 규칙 수는 기하급수적으로 증가하여 모델의 복잡성과 계산량의 증가와 같은 문제점을 가지고 있다.

본 논문에서는 이러한 단점을 보완하고 효율적인 데이터 의 처리를 위해서 모델의 성능 개선에 주요한 역할을 하는 파라미터를 PSO 알고리즘을 이용하여 최적화하였으며 우수 한 성능을 가지는 모델을 나타낼 수 있다.

그림 4는 $\mathrm{FCM}$ (Fuzzy C-Means Clustering)의 구조이다. 퍼지 규칙의 수가 많기 때문에 대략적으로 일부분의 구조만 을 나타낸 것이다.

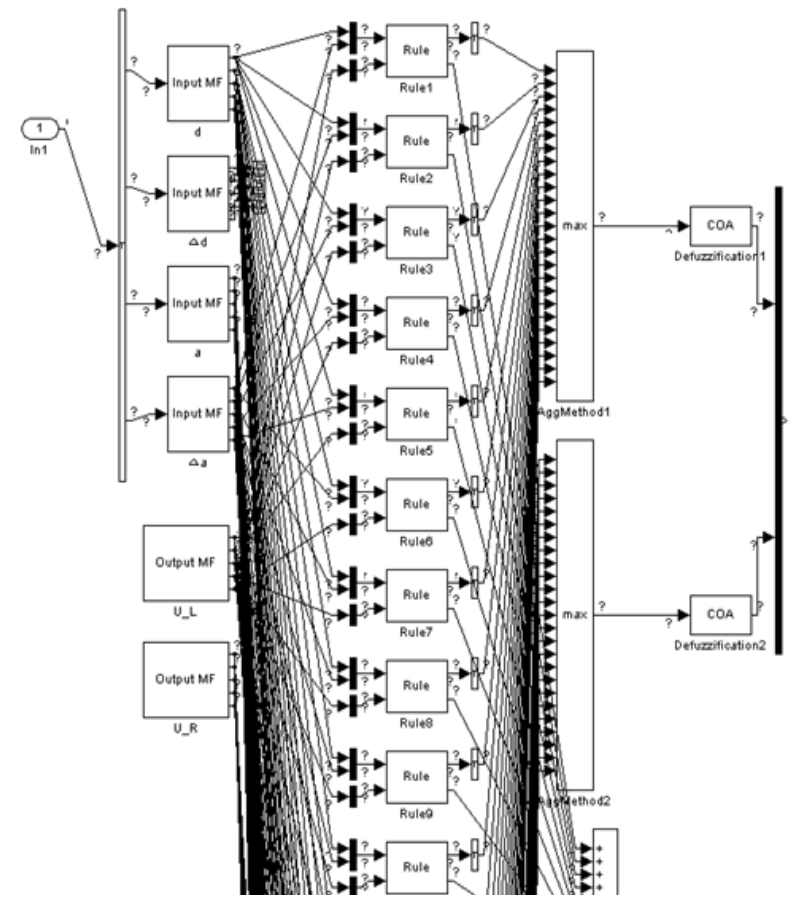

그림 $4 \mathrm{FCM}$ 구조

Fig. 4 Structure of FCM

$\mathrm{FCM}$ 의 목적 함수가 최소가 될 때 생성된 각 규칙에서 중심값을 찾는 방법으로 0 과 1 사이의 소속 정도에 의해서 나타난 소속감의 정도를 가지고, 주어진 데이터들을 몇 개의 규칙으로 나눌 수 있는지를 판별한다.

$\mathrm{FCM}$ 에 대한 목적함수는 식 (9)와 같다.

$$
J=\sum_{i=1}^{c} J_{i}=\sum_{i=1}^{c} \sum_{k=1}^{n} u_{i k}^{m}
$$

여기서, $u_{i k}$ 는 0 과 1 사이의 소속 정도를 나타내는 값으로 $\mathrm{i}$ 번째 규칙에 속한 $\mathrm{k}$ 번째 데이터의 소속 정도를 나타낸다. $m$ 은 애매함의 정도에 대한 영향을 나타내는 퍼지화 계수이 다.

전반부와 후반부의 소속 함수 $x_{1}, x_{2}, x_{3}, x_{4}$ 와 $y_{1}, y_{2}$ 는 식 (10)과 식 (11)로 각각 표현할 수 있다. 


$$
\begin{aligned}
& a_{(i, j)}=\left\{\begin{array}{ccc}
-x_{i}^{\max } \prod_{p=-j}^{j} k_{(j, p)} & \text { if } & -2 \leq j<0 \\
0 & \text { if } & j=0 \\
x_{i}^{\max } \prod_{p=-j}^{j} k_{(j, p)} & \text { if } & 0<j \leq 2
\end{array}\right. \\
& b_{(i, j)}=\left\{\begin{array}{ccc}
-y_{i}^{\max } \prod_{p=-j}^{j} k_{(j, p)} & \text { if } & -2 \leq j<0 \\
0 & \text { if } & j=0 \\
y_{i}^{\max } \prod_{p=-j}^{j} k_{(j, p)} & \text { if } & 0<j \leq 2
\end{array}\right.
\end{aligned}
$$

\section{4 모의실험}

본 논문에서 제안한 $\mathrm{PSO}-$ 퍼지 제어기를 이동 로봇에 적 용하여 경로 추적의 성능을 모의실험을 통하여 확인하였다. 모의실험에 적용된 이동 로봇은 로봇 축구에 일반적으로 사 용되는 모델과 같은 형태이다[8][9].

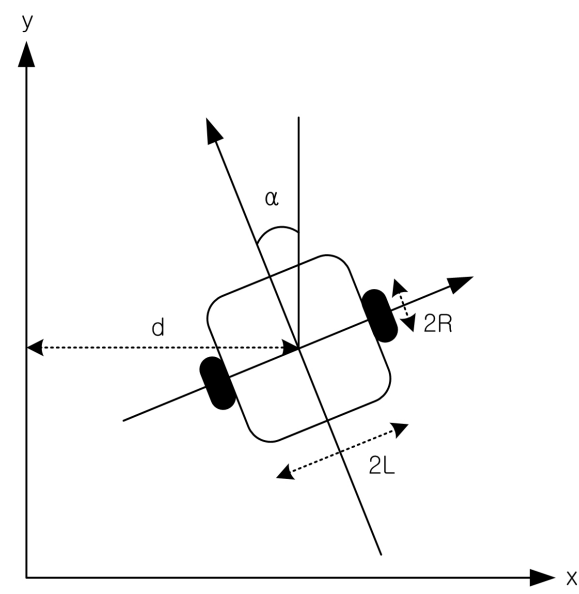

그림 5 이동 로봇

Fig. 5 Mobile Robot

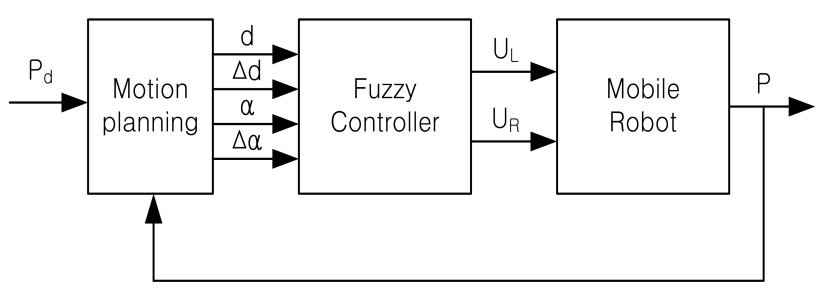

그림 6 퍼지 제어기 블록 다이어그램

Fig. 6 Fuzzy controller block diagram

이동 로봇의 구조는 그림 5 와 같다. 여기서, 이동 로봇의 구동 바퀴와 대칭축 사이의 거리는 0 이다. $d$ 는 기준선과 이 동 로봇의 무게 중심점 사이의 거리이고, $\alpha$ 는 조향각이고, $R$ 은 양쪽 구동 바퀴의 반지름이고, $L$ 은 대칭축과 구동 바퀴 사이의 거리이고, $m$ 은 이동 로봇의 무게이다.

모의실험에 사용한 이동 로봇의 파라미터는 다음과 같다.
표 2 PSO-퍼지 파라미터

Table 2 Parameters of the PSO-Fuzzy

\begin{tabular}{|c||c|}
\hline Parameter & Values \\
\hline \hline Generation & 200 \\
\hline Swarm & 40 \\
\hline$v_{\max }$ & 탐색공간의 $20 \%$ \\
\hline$w_{\max }$ & 0.9 \\
\hline$w_{\min }$ & 0.4 \\
\hline$c_{1}, c_{2}$ & 2.0 \\
\hline$m$ & $10(\mathrm{~kg})$ \\
\hline$L$ & $0.5(\mathrm{~m})$ \\
\hline$R$ & $0.05(\mathrm{~m})$ \\
\hline
\end{tabular}

본 논문에서는 제안한 이동 로봇의 제어기의 성능을 확인 하기 위하여 직선형 경로와 사인파형 경로에 대해 모의실험 을 하였다. 또한 기준이 되는 경로와 이동 로봇의 실제 경 로의 오차를 비교하여 기존의 퍼지 방법과 $\mathrm{PSO}$-퍼지 방법 의 성능을 비교하였다.

직선형과 원형 경로를 추적하는 경우 이동 로봇의 초기 위치는 $x(0)=0, y(0)=10$ 이고, 사인파형 경로를 추적하는 경우 이동 로봇의 초기 위치는 $x(0)=0, y(0)=25$ 이다.

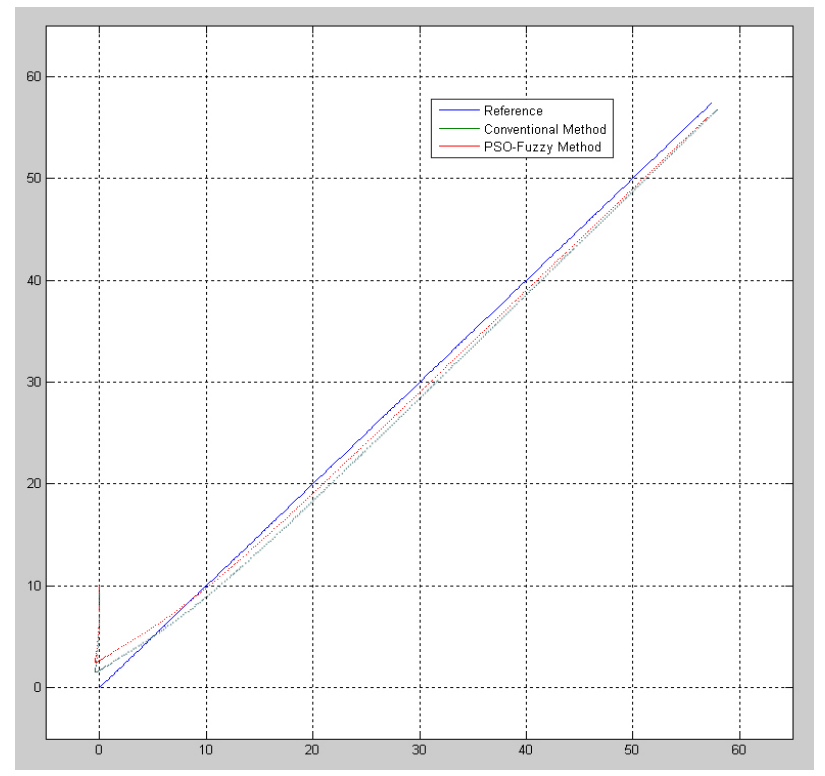

그림 7 직선형 경로 추적

Fig. 7 Linear trajectory tracking

그림 7과 그림 9에서는 직선형 경로와 사인파형 경로에서 의 각각 이동 로봇이 기준이 되는 경로를 추적함으로써 그 에 따른 추적 성능을 확인하였다. 여기서, 가로축은 $x[m]$ 이 고, 세로축은 $y[m]$ 이다.

각 그림으로부터 알 수 있듯이 $x, y$ 의 2 차 탐색공간에서 기준 경로를 추적할 때, 본 논문에서 제안한 PSO-퍼지 방 법의 수렴 성능이 더 우수한 것을 볼 수 있다. 


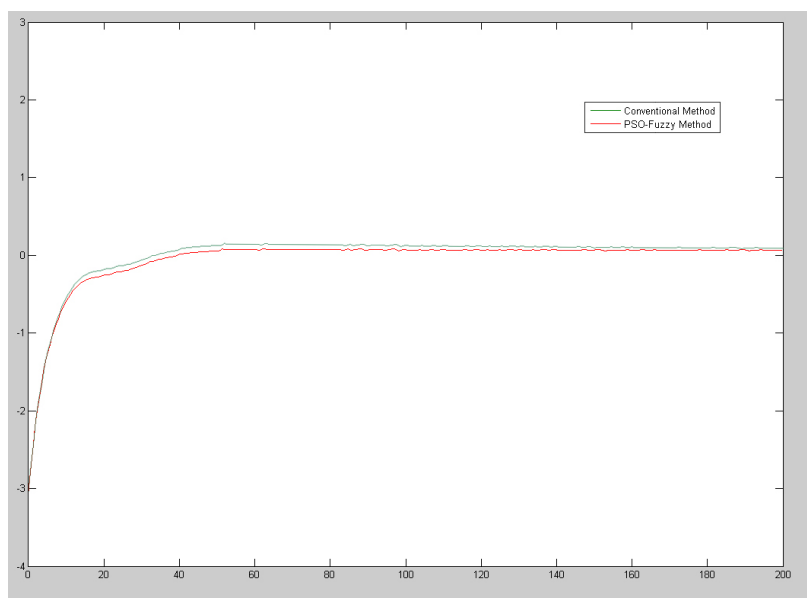

그림 8 직선형 경로 추적 오차

Fig. 8 Linear trajectory tracking error

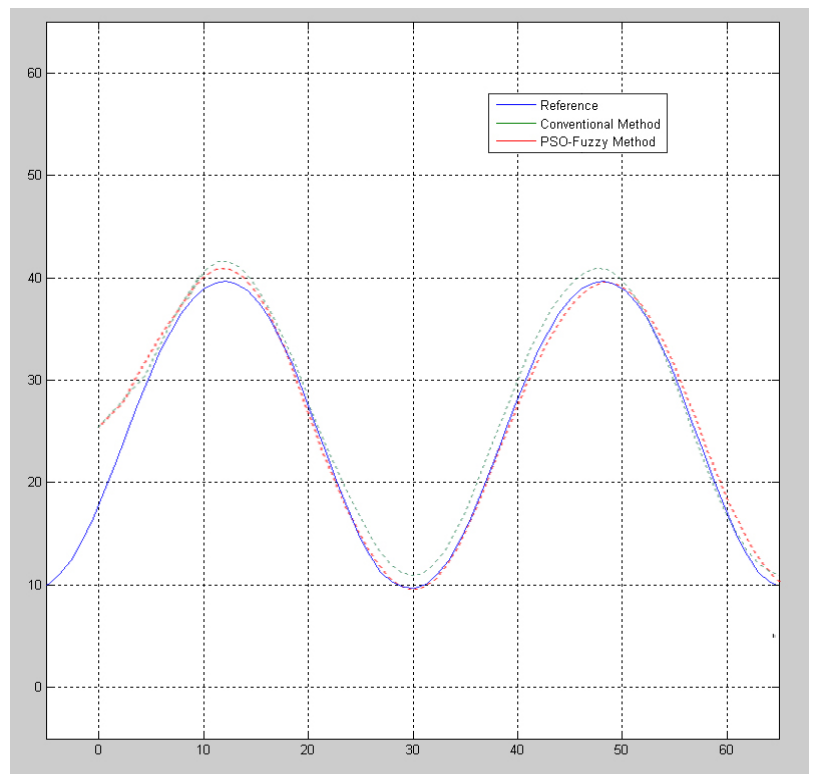

그림 9 사인파형 경로 추적

Fig. 9 Sin-shape trajectory tracking

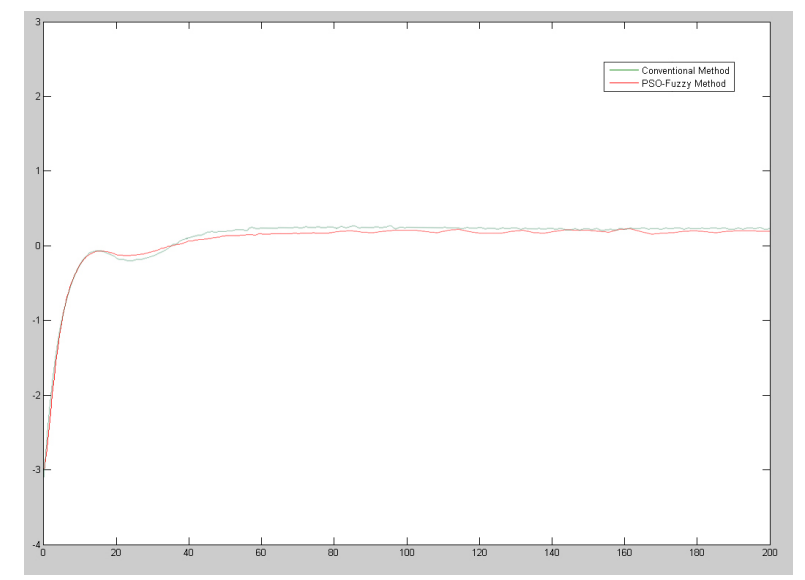

그림 10 사인파형 경로 추적 오차

Fig. 10 Sin-shape trajectory tracking error
그림 8 , 그림 10 에서는 각 제어기의 경로 추적 오차를 보 여주고 있다. 여기서, 가로축은 $\operatorname{error}[\mathrm{m}]$ 이고, 세로축은 Generation 이다. 기준 경로와 이동 로봇의 실제 경로의 오차 $x_{d}-x$ 와 $y_{d}-y$ 를 보여주는데, 각 그림에서 볼 수 있듯이 $\mathrm{PSO}-$ 퍼지 방법이 기존의 방법보다 빠른 수렴 속도와 작은 오차 값을 갖는 것을 확인 할 수 있다.

\section{3. 결 론}

본 논문에서는 퍼지 제어기와 $\mathrm{PSO}$ 알고리즘을 이용한 $\mathrm{PSO}-$ 퍼지 제어기를 설계하였다. 퍼지 제어기의 최적화를 위해 PSO 알고리즘을 사용하였고, 파라미터를 통해 퍼지 추론 시스템의 전반부 구조를 최적화 시켰다.

모의실험에서 볼 수 있듯이 직선형 경로와 사인파형 경로 를 안정적으로 수렴하고 있음을 알 수 있었고, 기존의 제어 기보다 초기 수렴이 빠른 것을 확인하였다. 또한, 기준 경로 와의 오차 값을 비교하였을 때 성능이 더 우수한 것을 볼 수 있었다.

\section{참 고 문 헌}

[1] J. Kennedy and R. Eberhart, "Particle Swarm Optimization," IEEE International Conference Neural Network, Vol. 4, pp. 1942 -1948, 1995.

[2] T. H. Lee, F. H. F. Leung, and P. K. S. Tam, "Position control for wheeled mobile robots using a fuzzy logic controller," IEEE International Conference on Industrial Electronics Society, Vol. 2, pp. 525-528, 1999.

[3] W. R .Hwang and W. E. Thompson, "Design of intelligent fuzzy logic controllers using genetic algorithms," IEEE World Congress on Computational Intelligence, Vol. 2, pp. 1383-1388, 1994.

[4] M. Clec and J. Kennedy, "The particle swarm explosion, stability, and convergence in a multidimensional complex space," IEEE Transactions on Evolutionary Computation, Vol. 6, pp. 58-73, 2002.

[5] Vikram Manikonda, P. S. Krishnaprasad and James Hendler, "A Motion Description Language and a Hybrid Architecture for Motion Planning with Nonholonomic Robots," IEEE International Conference on Robotics, Vol. 2, pp. 2021-2028, 1995.

[6] C. C. Wong and S. M. Her, "A self-generating method for fuzzy system design," Fuzzy Sets and Systems, Vol. 103, pp. 13-25, 1999.

[7] C. C. Chen and C. C. Wong, "Self-generating rule-mapping fuzzy controller design using a genetic algorithm," IEE Proceedings: Control Theory and Applications, Vol. 149, pp. 143-148, 2002.

[8] M. Bowling and M. Veloso, "Motion control in dynamic multi-robot environments," International Symposium on Computational Intelligence in Robotics and Automation, pp. 168-173, 1999. 
[9] F. Solc and B. Honzik, "Modeling and control of a soccer robot," IEEE International Workshop in advanced Motion Control, pp. 506-509, 2002.

\section{저 자 소 개}

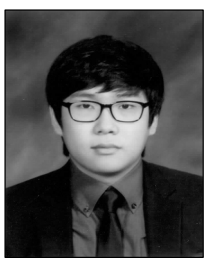

\section{김 두 현 (金 杜 鉉)}

1988년 3월 13일생. 2011년 호서대학교 국방과학기술학과 졸업(학사). 2011년 현재 한양대학교 전자전기제어계측공학 과 석사과정.

Tel : 031-436-8118

Fax : 031-436-8117

E-mail : enxod@hanyang.ac.kr

\section{한 병 조 (韓 秉 祚)}

1979년 11월 24일생. 2006년 영동대학교 전자공학과 졸업(학사). 2006년 현재 한 양대학교 전자전기제어계측공학과 석 · 박사 통합과정 박사수료. 관심분야 비선 형 시스템.

Tel : 031-436-8118

Fax : 031-436-8117

E-mail : help7@hanyang.ac.kr

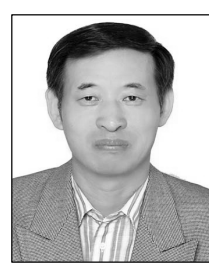

\section{이 석 용 (李 錫 容)}

1960년 3월 25일생. 1986년 한양대학교 전기공학과 졸업(학사). 2000년 한국기술 교육대학교 전기전자공학과 졸업(석사). 2012년 한양대학교 전자전기제어계측공 학과 졸업(박사). 현재 (주)삼현 상무이 사. 관심분야 제어 및 시스템 응용, 공장 자동화, 로보틱스.

Tel : 031-436-8118

Fax : 031-436-8117

E-mail : lm8619@unitel.co.kr

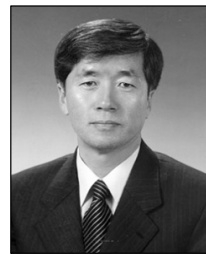

\section{양 해 원 (梁 海 元)}

1950년 3월 20일생, 1971년 서울대학교 전기공학과 졸업(학사). 1973년 동 대학 원 전기공학과 졸업(석사). 1982년 일본 Kyoto대학교 전기공학과 졸업(박사). 1986년 현재 한양대학교 전자컴퓨터공 학부 교수. 1993년 미국 Yale 대학 방문 교수.

Tel : 031-436-8118

Fax : 031-436-8117

E-mail : hwyang@hanyang.ac.kr 